observe and calculate in bothisystems the same large lot of angles. It was then found that the use of decimals gave a saving of two-sevenths of time either in observation or in calculation. This result was unknown to Sir George Airy, the ablest astronomer of our time, but he judged rightly that the conversion of all sexagesimal angles into decimal ones would materially lighten his labours, and he actually did so when calculating all the lunar observations previously made at Greenwich. This was the largest quantity of reductions ever made by one astronomer, and they were abridged by the use of decimals. The real supporter of sexagesimal divisions is routine, that sly enemy of progress. Abbadia, November 2 ANTOINE D'ABBADIE

\section{Christian Conrad Sprengel}

IT has now become a standing topic that C. C. Sprengel's treatise on the structure and fertilisation of flowers "after well nigh a century of oblivion has come to be recognised as one of the most interesting books, and his theory of the adaptation of flowers to fertilisation by insects is one that will ever be associated with his name" (NATURE, vol. xxviii. p. 5I 3). Some writers go so far as to speak of a rediscovery of Sprengel's treatise by Darwin. But it should be acknowledged that Darwin himself says only ("Cross Fertilisation," p. 5): "His discoveries were for a long time neglected." So it seems to be true that Sprengel's and Koelreuter's works were unknown to English naturalists, though Kirby and Spence, at the end of Letter IX., published 18 I5, and in all subsequent editions till 1867 , have given a very fair report in their masterly manner. Not only the facts, but also the importance of these discoveries, are fairly expounded.

In Germany these discoveries were well known to every naturalist during the whole century. In 1829 , when a mere boy, my father began to instruct me in entomology. Many times he took Sprengel's work from the shelves in his study, and explained to me the discovery of fertilisation of plants by insects with the help of the plates in Sprengel's book. I have never forgotten the interest and the scientific enthusiasm of his exposition. I was told that we are indebted to a mere chance for this discovery. A rather dangerous irritation of Sprengel's eyes had the result that he was entirely forbidden indoor study by his physician, and was therefore obliged to spend his days in the field, where he was gradually led to the observation of plants, followed by his remarkable discoveries. Certainly between 1830 to 1840 at every university in Prussia the same facts were taught as well known facts of the highest importance, and of course known by every student. Prof. C. F. Burdach has related them in his large "Physiology," vol. i. p. 322, 1826, and given his conchisions. H. Burmeister, "Handb. d. Entomologie," vol. i. p. 303, 1832, speaks about them at some length also as well known and of the highest importance. Not only scientific publications, but merely popular works have the same statements. Pierer's "Universal Lexicon" (first edit. 1836, fourth, 1851, vol. ix. p. 942) gives a fair report.

Cambridge, Mass., October 23

\section{"Challenger" Zoological Reports}

IT seems to me that the reviewer of my Report on the Pelagic Hemiptera collected during the voyage of the Challenger (NATURE, vol. xxix. p. 3) is too hypercritical.

I refer, of course, to the paragraph in which he blames me for alluding to species under their trivial names only; and as the paragraph in question is calculated to convey a wrong impression, I should be obliged if you will kindly allow me to say a word on the subject.

It is true that some writers upon insects (or rather upon Lepidoptera only) have the very bad habit of alluding to species (of different genera) by their specific names only, and the law that forbids the practice is a good one ; but it may be applied too stringently, and not altogether in the sense that its framers intended.

In my Report I had to deal with two genera, and a reader of the review who had not seen the Report itself would be justified in concluding from the words of the reviewer that I have used the specific names indi-criminately, without indicating the genus to which the species belonged. In point of fact this is not the case. The two genera are treated of separately, and where I have mentioned the trivial without the generic name, it has only been when the generic name governed the paragraph, and, when, consequently, no doubt could possibly exist as to the genus. In doing so I may have broken the letter of the law, but not, I think, the spirit; and were the work to be done over again, I think I would be inclined to follow the same course.

\section{F. Buchanan White}

[The idea of a generic term governing a paragraph did not strike me. I had no wish to be over-critical, and I am glad to find that in all essentials Dr. Buchanan White agrees with the views expressed. -ThE W'Riter of THE Notice.]

\section{Barytes from Chirbury}

A NUMBER of crystals of barytes have Jately been acquired by Mr. Henson from Chirbury, Salop, which seem to deverve some description. The crystals vary from one to four inches in length and from one-half to two inches in breadth; they are very bright and clear, and are elungated in the direction of the brachydiagonal, resembling in appearance the barytes from Dufton; they are mostly doubly terminated, and some contain included crystals of copper pyrites. They were at once detected by $\mathrm{Mr}$. $\mathrm{T}$. Davies as being peculiar in form; and the reflecting goniometer revealed the existence upon them of four very well-defined forms which have not been hitberto found upon barytes, besides two more doubtful planes to which it is difficult to assign definite symbols.

The crystals are almost all a combination of the forms-

$$
\begin{aligned}
& o\{101\} \breve{\mathrm{P}}_{\infty} \\
& d\{012\} \frac{1}{2} \overline{\mathrm{P}}_{\infty} \\
& m\{110, \infty \mathrm{P} \\
& l\{014\} \frac{1}{4} \overline{\mathrm{P}}_{\infty} \\
& u\{01 \mathrm{I}\} \overline{\mathrm{P}}_{\infty} \\
& a\{100\} \infty \mathrm{P}_{\infty} \\
& b\{010\} \infty \overline{\mathrm{P}}_{\infty} \\
& c\{01\} \circ \mathrm{P}
\end{aligned}
$$$$
\begin{aligned}
& \mathrm{E}\{4 \mathrm{I} 2\} 2 \mathrm{P}_{4} \\
& y\{2 \mathrm{I} 2\} \breve{\mathrm{P}}_{2} \\
& z\{\mathrm{III}\} \mathrm{P} \\
& \xi\left\{232^{\prime}, \frac{3}{2} \overline{\mathrm{P}}_{2}\right. \\
& \omega\{432\} 2 \breve{\mathrm{P}}^{4}
\end{aligned}
$$

On some crystals were also observed-

$$
\begin{aligned}
& \mu(2 \mathrm{I} 4) \frac{1}{2} \mathrm{P} 2 \text { between } d \text { and } o \\
& r \text { (II }) \frac{1}{2} \mathrm{P} \text { between } d \text { and } y \\
& Z \text { (O34) } \frac{3}{4} \overline{\mathrm{P}} \infty \text { between } u \text { and } d .
\end{aligned}
$$

The general appearance of the crystals is shown in the annexed figure.

Of the above faces $\xi, \omega, E$, and $Z$ are new. $\xi$ lies with parallel

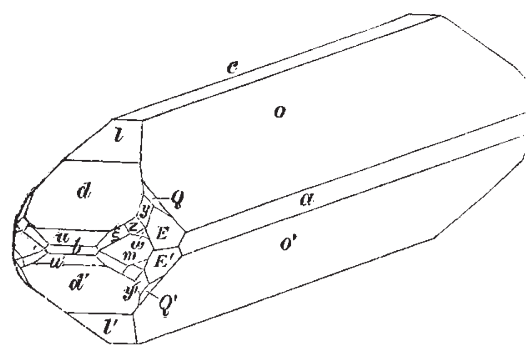

edges between the faces $d m$ and $z b$, and is very dull : $\omega$ lies between $y m$ and $z o^{\prime}$; E between $y a$ and $o z^{\prime}$.

Several of these crystals have also a small dull face $Q$ lying with parallel edges between $o$ and $y$, and on one this is accompanied by another small dull face $Y$ between $o$ and $m$. By oiling these faces it was possible to determine approximately their inclination to 0 . The measurements lead to the complicated symbols (15.1.15) for $Q$ and (I9.1.18) for Y.

The new faces, and especially $E$, are very characteristic of these specimens, and it is somewhat curious that faces with the simple symbols of $\xi, \omega, E, Z$, have not hitherto been noticed among the sixty-six recorded forms of barytes.

Mineral Department, British Museum, October 25 